Conclusions PCB is a benign condition, with characteristic clinical and histopathological features. Although various treatment modalities have been used, circumcision remains the treatment of choice. PCB is an expression of dysfunctional foreskin, moreover the curative effect of circumcision in $100 \%$ of our patients suggests that it is a nonspecific reactive balanitis caused by a disturbed "preputial-ecology.

\section{P2.134 OPHTHALMIC AND OTOLARYNGOLOGICAL MANIFESTATIONS OF SYPHILIS IN PATIENTS WITH HIV}

doi:10.1136/sextrans-2013-051184.0398

II A Orlova, II O Smirnova, 'A V Korobko, "Y G Petunova, ${ }^{2 T}$ S Smirnova, ${ }^{2} \mathrm{~V} U$ Dudko, ${ }^{2}$ V Litvinenko, ${ }^{2} \mathrm{~A}$ B Piryatinskaya, ${ }^{2} \mathrm{~N}$ V Smirnova. ${ }^{1}$ Saint-Petersburg State University, Medical Faculty, Saint-Petersburg, Russian Federation; ${ }^{2}$ Saint-Petersburg Dermatovenerologic Dispensary, Saint-Petersburg, Russian Federation

Background Recently noteworthy aspect of the problem is associated with an increase in cases of syphilis as part of mixed infection including HIV. Mixed infection syphilis and HIV alters the clinical picture and prognosis of both diseases.

Methods 316 patients with early forms of syphilis were treated in city hospital in St. Petersburg in 2006-2010. The study group included 153 patients with syphilis + HIV (10 - primary syphilis, 117 - secondary syphilis, 26 - early neurosyphilis). Control group 163 patients with syphilis (14 - primary syphilis, 115 - secondary syphilis, 34 - early neurosyphilis). Ophthalmic and otolaryngological manifestations of syphilis were estimated.

Results Ophthalmic and otolaryngological manifestations of syphilis were diagnosed in $18(11.8 \%)$ patients of study group and 4 $(2.5 \%)$ - control group $(p<0.05) .12$ and 2 patients with secondary syphilis, 6 and 2 patients with early neurosyphilis of study and control group respectively.

In none of the groups ophthalmic and otolaryngological manifestations in patients with primary syphilis were not determined. Specific papillitis $(5(3.3 \%))$ and specific panuveit $(5(3.3 \%)$ as well as specific laryngeal neuropathy $(1(0.6 \%))$ and specific bilateral hypoacusis $(1(0.6 \%))$ were identified only in study group. Specific anterior uveitis was detected in both groups (1 and 2 patients), specific angina (3 and 1 patients) and specific laryngitis (monochorditis) (2 and 1 patients) of study and control group respectively.

Among 18 patients of study group with ophthalmic and otolaryngological manifestations were 12 cases of secondary syphilis and 6 - early neurosyphilis. 1 patient showed simultaneous ophthalmic, otolaryngological disorders and diffuse neurological symptoms.

Conclusion Clinical manifestations of syphilis were more varied in patients with HIV. Ophthalmic and otolaryngological manifestations of syphilis were more common in patients with mixed infection syphilis + HIV, which may indicate a more severe course of syphilis in these patients.

\section{P2.135 SITUATION OF SEXUALLY TRANSMITTED INFECTIONS IN MOST HIV/AIDS RISK POPULATIONS (MARPS) IN 8 PROVINCES IN VIETNAM}

doi:10.1136/sextrans-2013-051184.0399

${ }^{1} \mathrm{~K}$ H Tran, ${ }^{1} \mathrm{H}$ D Nguyen, ${ }^{1} \mathrm{P}$ M T Pham, ${ }^{1} \mathrm{H}$ Quach, ${ }^{2} \mathbf{T}$ T Vu, ${ }^{2} \mathrm{~N}$ T T Do, ${ }^{2} \mathrm{~A} 0$ Chu. ${ }^{1}$ National hospital of dermatology and venereology, ha noi, Viet Nam; ${ }^{2}$ Viet Nam - USA collaboration HIVIAIDS Project on Prevention and Care (LIFE-GAP project) in Vietnam, Ministry of Health, ha noi, Viet Nam

Background Many studies show, STIs have a closed relation with HIV. STI increases the risk of getting HIV, HIV infection makes STIs more difficult to diagnose, treat. From 2011-2012, STI services were provided to most-at-risk populations (MARPs) in 8 provinces in Vietnam by the support from CDC/PEPFAR. The MARPs included commercial sex workers (CSWs), men have sex with men (MSM) and injecting drug users (IDUs).
Method A descriptive cross sectional study of 5187 MARPs in 8 provinces in Vietnam was undertaken from 10/2011-9/2012 to determine the prevalence of STIs in specific MARPs.

Results Among 5187 MARPs screened for STIs, 4,119 MARPs (79.4\%) had STIs. Among STIs patients recorded, CSW had the highest proportion (83\%), followed by IDUs (16\%) and MSM only $1 \%$.

Among STI patients, 59.7\% ( $\mathrm{n}=2461)$ were diagnosed by syndromic approach and $40.3 \%$ by etiologic approach. In the group of syndromic diagnosis: Among 2,105 CSWs recorded, 51.7\% had vaginal discharge and 7.9\% had genital ulcer. Among 353 IDUs, $89.4 \%$ had urethral discharge and the proportion of genital ulcer was accounted for only $0.6 \%$. Regarding MSM, all of them have urethral discharged $(n=3)$.

In the group of etiologic diagnosis: Among 1,313 CSWs tested to detect STI, $28.9 \%(n=379)$ had bacterial vaginitis, $22.7 \%(n=298)$ had vuvovaginal Candidiasis, $2.2 \%(\mathrm{n}=30)$ had genital Chlamydia infection, and $1.2 \%(\mathrm{n}=16)$ had vaginal Trichomoniasis. $26.9 \%$ $(n=352)$ of the CSWs had genital wart. Among 303 IDUs, 32.6\% $(\mathrm{n}=100)$ had genital wart, $17.9 \%(\mathrm{n}=55)$ had gonorrhoea and $11.1 \%(n=41)$ had genital HSV infection. Among 42 MSM, 85.7\% $(\mathrm{n}=36)$ had genital warts and, $7.1 \%(\mathrm{n}=3)$ had gonorrhoea.

Conclusion Vaginal discharge syndrome was the most common syndrome among CSWs, urethral discharge was the most common syndrome among IDUs. Among CSWs, the most common STIs were bacterial vaginitis, HPV. Among IDUs and MSM, the most common STIs was HPV.

\section{P2.136 SEXUAL TRANSMISSION INFECTION SITUATION IN PEOPLE LIVING WITH HIV (PLHIV)IN 6 PROVINCES IN VIETNAM FROM 2008-2011}

doi:10.1136/sextrans-2013-051184.0400

${ }^{1} \mathrm{~K}$ H Tran, ${ }^{\mathbf{P}} \mathbf{M}$ T Pham, ${ }^{1} \mathrm{H} \mathrm{D}$ Nguyen, ${ }^{1} \mathrm{H}$ T Quach, ${ }^{2} \mathrm{~T}$ T Vu, ${ }^{2} \mathrm{~N}$ T Do, ${ }^{2} \mathrm{~A} 0 \mathrm{Chu}$ ${ }^{1}$ National hospital of dermatology and venereology, ha noi, Viet Nam; ${ }^{2}$ Viet Nam - USA collaboration HIVIAIDS Project on Prevention and Care (LIFE-GAP project) in Vietnam, Ministry of Health, ha noi, Viet Nam

Background Multiple studies have suggested that STIs (sexual transmission infections) are important cofactors in the transmission and acquisition of HIV infection. Thus control of one may have beneficial effects on the control of the other.

Method A descriptive cross sectional study of 2059 PLHIV and STIs were undertaken at 6 at adult HIV outpatient clinics in Vietnam from $10 / 2008$ to $11 / 2011$ to determine the STIs situation among PLHIV.

Results Among 2059 PLHIV and STIs 48.2\% ( $\mathrm{n}=991)$ were male, $51.8 \%(n=1068)$ were female. The majority of PLHIV with STIs $(\mathrm{n}=2010,97.6 \%)$ are the ages of from 15 to 49 years, only $2.4 \%(n=49)$ of patients over 49 years. $65.6 \%(n=1350)$ of patients are diagnosed STI by etilogic approach. $34.4 \%(n=709)$ of STI/HIV patients were diagnosed by syndromic approach. Among 336 male patients ( $n=47.4 \%$ ) diagnosed with STIs by syndromic approach: $(80.1 \%)(\mathrm{n}=269)$ patients had urethral discharge syndrome, $(19.4 \%)(n=65)$ patients had genital ulcer syndrome. Among 373 female patients $(n=52.6 \%)$ diagnosed with STIs by syndromic approach, $\mathrm{n}=190(50.9 \%)$ patients had vaginal discharge syndrom, $\mathrm{n}=148(39.7 \%)$ had abdominal pain syndrome. Of 655 male patients etiologically diagnosed of STI, $65.7 \%(\mathrm{n}=430)$ had genital warts with human papillomavirus (HPV), $\mathrm{n}=73(11.2 \%)$ had genital ulcers due to Herpes simplex virus (HSV), $\mathrm{n}=38(5.8 \%)$ had gonorrhoea, $\mathrm{n}=22(3.4 \%)$ had Chlamydia trachomatis $3 \%$. Of 695 female patients, $\mathrm{n}=295$ (42.4\%) had warts due to HPV, $\mathrm{n}=121(17.4 \%)$ had fungal vaginitis due to Candida, $\mathrm{n}=117(16.8 \%)$ had bacterial vaginalis and $\mathrm{n}=79(11.4 \%)$ had ulcers due to HSV. 